\title{
Exchange Rate Pass-Through in Vietnam under the Impact of Inflationary Environment
}

\author{
TRAN NGOC THO \\ University of Economics HCMC - thotcdn@ueh.edu.vn \\ NGUYEN THI NGOC TRANG \\ University of Economics HCMC - trangtcdn@ueh.edu.vn
}

\section{ARTICLE INFO ABSTRACT}

Article history:

Received:

Aug. 022015

Received in revised form:

Sep. 252015

Accepted:

June 202016

Keywords:

Exchange rate passthrough, inflation threshold, TVAR,

Vietnam.
This article addresses the exchange rate pass-through to domestic prices under the impact of inflation. Using TVAR based approach and the variables of inflation, nominal effective exchange rate (NEER), output gap, and interbank rate in addition to monthly data applied to the period of 2000M1-2014M12, we find a non-linear relation in the pass-through to inflation along with the two thresholds of its. Being above or below the thresholds results in different levels of the exchange rate pass-through, which is consistent with previous findings, with unclear/clear evidence found below/above the threshold of $0.3395 \% /$ month respectively. In the case of positive shocks of the exchange rate, the inflation is suggested to enormously rise and then return to equilibrium. We also attempt to clarify several distinct features of Vietnam affecting the pass-through and draw a few implications. 


\section{Introduction}

Many studies in the world have performed analyses of inflation in its response to changes in exchange rate. They also found reasons for low levels of exchange rate passthrough during the $80 \mathrm{~s}$ and $90 \mathrm{~s}$, and pondered a potential linkage between inflationary environment and the pass-through. Taylor (2000) detected the low pass-through that cannot be perceived to be "exogenous to inflationary environment." Afterward, a few researches attempted to examine the robustness of this argument, exploring a positive correlation between these two factors (Calvo \& Reinhart, 2002; Choudri \& Hakura, 2006; Devereux \& Yetman, 2010).

Recently several investigations into the case of Vietnam, including Vo (2009), Nguyen et al. (2010), and Nguyen and Nguyen (2010), were conducted to measure the pass-through in relation to lower and higher exchange rates that involve variance in price indices, using various techniques of vector autoregression (VAR), structural vector autoregression (SVAR), or vector error correction model (VECM). However, all of these base themselves on the assumption of a linear relation, which means that the pass-through coefficient remains constant under the impact of inflationary environment.

Yet, agents in the economy, in reality, tend to change inflation expectations if inflation rates exceed certain threshold levels. Firms notice that any increase in production costs that goes beyond necessary thresholds will become more persistent along with the existence of high inflation. Thus, in a high-inflation environment these businesses would adopt higher price-adjustment frequency providing menu costs are fixed. They also transmit effects arising from shocks to maintain their profits. Under the circumstance of other factors being unchanged, due to increased price-adjustment frequency, only a small devaluation would result in a rapid rise in domestic prices. Consequently, the levels of exchange rate pass-through to domestic prices are higher in periods of high-inflation than low-inflation times.

A few intervals over the period of 2000-2014 saw the State Bank of Vietnam implement devaluation with their varied effects on consumer price index (CPI) (Figure 1). Empirical analyses, hence, are crucial to adequately solve the puzzle: Does inflationary environment cause changes to coefficient of exchange rate pass-through to domestic price index? 


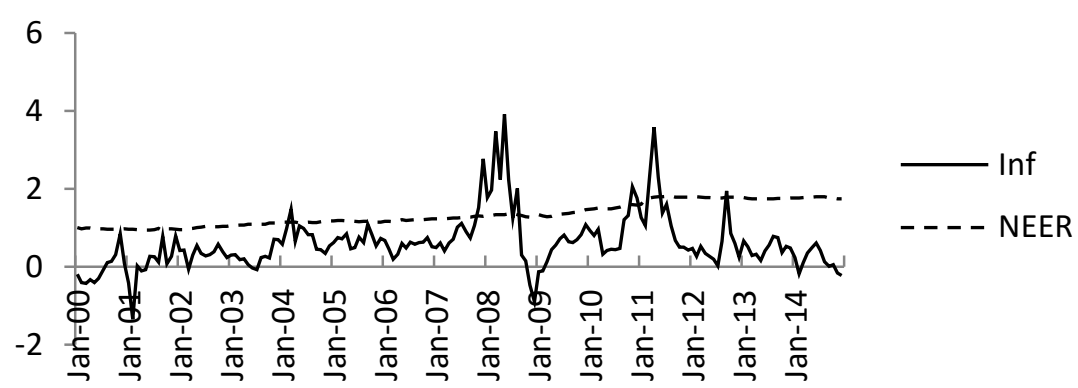

Figure 1. Nominal effective exchange rate (NEER) and inflation rate fluctuations between 2000 and 2014

Source: estimations using IFS and Datastream

Unlike earlier studies on the same country, this study aims to highlight the impact of inflationary environment on exchange rate pass-through in Vietnam. Following the findings of Aleem and Lahiani (2014), we employ monthly data series of NEER, CPI (proxy for domestic price), output gap (proxy for real economy), and interest rate (proxy for monetary policy) to estimate the levels of exchange rate pass-through during the 2000-2014 period. The dataset, collated from IFS, Datastream, and General Statistics Office of Vietnam (GSO), is processed by TVAR approach with the help of such statistical packages as Matlab, Gretl, and Eview.

\section{Theoretical framework}

\subsection{Staggered pricing model with market power}

Introduced by Taylor (2000), the model is grounded on a bold hypothesis that change in market power partly due to change in persistence in price movements and costs and change in pricing power is subject to different levels of exchange rate pass-through to inflation. The reasoning has been supported by a stream of empirical evidence, which suggests a nonlinear relation of exchange rate pass-through and a connection between low inflation and low pricing power by adopting a model proposed below: 


$$
x_{t}=\sum_{i=0}^{3} 0,125\left(E_{t} c_{t+i}+E_{t} p_{t+i}+E_{t} \varepsilon_{t+i} / \beta\right)
$$

where $x_{t}$ is optimal price at period $t, c_{t+i}$ is marginal cost at period $t+i$, and $\mathrm{p}_{\mathrm{t}+\mathrm{i}}$ is average price set by four groups of firms at period $t+i$.

The model implies that price estimates are dependent on expectations of future costs and price movements. If increase in prices is expected to be persistent, there should be adjustments at higher levels and frequency to balance the costs. For this reason pricing power is contingent on inflation expectations. Concerning a firm requiring inputs for manufacturing, the marginal cost $c_{t}$ links itself with exchange rate. However, for a retail company the import of goods is considered an intermediate factor, based on which it may add in total values in the form of retail services. A drop in domestic currency gives rise to increased import costs estimated in domestic prices. If the devaluation is believed to be temporary (compared to inflation), firms tend to transmit a small proportion of decreased domestic currency value into prices (in the form of increased optimal price$x_{t}$ ). Therefore, less persistence in exchange rate movements will result in smaller passthrough coefficient.

\subsection{Mark-up model}

Mark-up approach has been commonly adopted by Al-Abri and Goodwin (2009), Barhoumi (2006), and Campa and Goldberg (2005) in their investigating exchange rate pass-through. According to the literature, import price is a function of exporter's markup $\left(m k u p^{x}{ }_{t}\right)$ and marginal cost $\left(m c^{x}{ }_{t}\right)$. This theory was extended by Junttila and Korhonen (2012), assuming that change in the monetary policy of importing country will become a decisive factor in adjusting the exporter's mark-up, and thus regarding the mark-up $\left(\operatorname{mkup}_{t}{ }_{t}\left(S_{t}\right)\right)$ as "a function of the monetary policy stance." It is assumed that the exporting firm sets prices for a few terms beforehand. Mark-up of the firm would elicit stronger response to variance in exchange rate in case of high inflation; therefore, a highinflation environment is more likely to lead to increased exchange rate pass-though. To further detail the markup, Junttila and Korhonen (2012) utilized the multiplicative form expressed as $\theta\left(\pi_{t}\right) e_{t}$, in which $\theta$ denotes a nonlinear function of consumer price inflation of the importing country $\pi_{t}$ as follows:

$$
P_{t}^{I M}=\theta_{1} e_{t}+\theta_{2}\left(\pi_{t}\right) e_{t}+\theta_{3} m c^{x}{ }_{t}
$$

where $P_{t}^{I M}$ is import price at period $t$, and $\theta_{1}, \theta_{2}$, and $\theta_{3}$ are positive parameters. 
The above equation indicates that indirect effects are exerted by exchange rate variance, depending on the importing country's inflationary environment. Assuming that two inflation regimes (high and low inflation) are imposed on the importing country and that $\pi^{*}$ is inflation threshold value, we can refer to the low inflation regime $\left(\pi_{\mathrm{t}}<\pi^{*}\right)$ as the environment featuring so high competitiveness that it could abandon a pricing-tomarket strategy adopted by the exporting enterprise. In such circumstance the indirect exchange rate pass-through reaches zero, and the enterprise will directly pass all exchange rate movements to the price having been set. On the other hand, the high inflation regime $\left(\pi_{\mathrm{t}}>\pi^{*}\right)$ is such that the pricing-to-market strategy can be fully employed, and that the level of the exchange rate pass-through is larger than zero. To be more specific, the high inflation could be matched by a rise in coefficients of exchange rate pass-through in a nonlinear fashion.

\section{Empirical evidence of nonlinear exchange rate pass-through}

Most recent studies focused on examining Taylor's (2000) reasoning about the role of inflation in impacting exchange rate pass-through. One typical example is Gagnon and Ihrig (2001), who explored the relation between the pass-through of exchange rate to CPI and inflation stabilization among twenty industrial countries and found a decline in the levels of pass-through in the 90s in addition to its change, which is statistically significantly related to inflation. However, no systematic nexus between the exchange rate pass-through and monetary policy behavior was detected.

Choudhri and Hakura (2006) extended the research scope with a sample of 71 countries, including developing countries, over the period of 1979-2000. Using new open economy macroeconomic models, they estimated an average inflation rate for each country and categorizing them into low- and high-inflation groups to measure passthrough levels accordingly. A positive and significant association was found between the pass-through and the average inflation rate.

By developing a simply model to account for the pass-through estimates in light of constantly adjusted and sticky prices for a dataset of more than 100 countries, Devereux and Yetman (2010) found a positive yet nonlinear relationship between the exchange rate pass-through and average inflation. This nonlinear manner in the analysis is derived from the annual inflation rate rising above certain threshold, which entails no further inflation effects on the pass-through as adjustments are made to all prices in each term, 
and the pass-through is also suggested to be "approximately complete." A small change is not likely to cause price fluctuations in the country with local currency pricing thanks to price adjustment or contract re-negotiation costs. In spite of this, a great and persistent shock might trigger the exercise of price adjustment in some enterprises, and it could be deemed a variance in pass-through elasticity.

Aleem and Lahiani (2014) provided further evidence on nonlinear exchange rate pass-through in Mexico, using TVAR approach for the underpinning of inflation threshold. They arrived at the conclusion that different inflation regimes lead to different levels of the exchange rate pass-through.

The above typical researches have been carried out in different periods for the cases of either OECD member countries, a mix of developed and developing countries, or a single specific country. Even if different techniques and/or approaches were adopted, similar results could be attainable, confirming the impact of inflationary environment on exchange rate pass-though (lower rates of pass-through resulted from low-inflation environment). Various explanations were also provided; yet, ample evidence was clearly shown of nonlinear mechanism of the pass-through to domestic CPI.

Several authors in Vietnam recently study the issue of exchange rate pass-through, including Vo (2009), Nguyen et al. (2010), Nguyen and Nguyen (2010), Tran and Nguyen (2012), and Nguyen and Luc (2012). Using diverse methods including VAR, VECM, and OLS, the researchers demonstrate that the pass-through to domestic prices is incomplete, but have not addressed the pass-through-inflation linkage, which becomes a gap for further investigation. Thus, the present study attempts to provide a more vivid insight into the pass-through of exchange rate in the similar context of Vietnam.

\section{Data and methodology}

Although linear VAR approach is quite effectively dealing with econometric issues, the nonlinear one proves more suitable in other aspects, as in real practice of certain economic theories that require its adoption or non-linear relations among the variables that are indicated by the data series. For more examples, recent financial crises show that the quantitative relationships among macroeconomic variables in the economy demand instead the nonlinear modeling, or its usefulness is shown in the analysis of monetary policy, whose positive or negative shocks may have asymmetric effects on the economy, 
and of high or low inflation environment, which also impacts on the exchange rate passthrough to inflation, signaling a certain nonlinear relationship. The nonlinear VAR model, in addition, plays a key role in examining effects of fiscal policy, mostly dependent on different phases of the business cycle. Studying fiscal multiplier effects may involve employing nonlinear instruments (Hubrich \& Teräsvirta, 2013).

Different approaches can be adopted for modeling nonlinear relations. The common measures include threshold vector autoregressive (TVAR), vector smooth transition autoregressive (VSTAR), and vector Markov-switching autoregressive (VMSAR) models. The difference among these models lies in observable and unobservable variables, as remarked by Hubrich and Teräsvirta (2013). Deciding between TVAR and VSTAR estimators relies on specific economic issues that need examining. While the former is developed to address the cases "where the dynamic behavior of a set of random variables can be modeled by defining a limited number of linear states or regimes that the process can visit," the latter can be employed when "the dynamic behavior of the variables changes smoothly between a number (often two) extreme states or regimes (Hubrich \& Teräsvirta, 2013)."

The objective of this research is to investigate the impact of inflationary environment on exchange rate pass-through and whether the latter varies under the influence of the former. The study, nevertheless, does not account for the smooth change among inflationary environments. Thus, only when the nonlinear relationship is found between inflation and the exchange rate pass-through is the suitability of TVAR technique demonstrated.

For the above reasons and based on Aleem and Lahiani's (2014) literature, we adopt the multivariate TVAR approach. Through the model the fact can be underlined that exchange rate volatility may alter the response of economic entities to volatilities and result in different levels of response depending on different inflation rates.

\subsection{TVAR approach modeling}

Three of the TVAR regimes are presented as follows:

$$
\begin{aligned}
y_{t}=\left(\alpha_{1}+A_{11}(L) y_{t-1}+\cdots+A_{1 p}(L) y_{t-p}+\varepsilon_{1 t}\right) I\left(q_{t} \leq \gamma_{1}\right) \\
+\left(\alpha_{2}+A_{21}(L) y_{t-1}+\cdots+A_{2 p}(L) y_{t-p}+\varepsilon_{2 t}\right) I\left(\gamma_{1}<q_{t} \leq \gamma_{2}\right) \\
+\left(\alpha_{3}+A_{31}(L) y_{t-1}+\cdots+A_{3 p}(L) y_{t-p}+\varepsilon_{3 t}\right) I\left(q_{t}>\gamma_{2}\right)
\end{aligned}
$$


where the vector of $y_{t}$ comprises inflation, output gap (capturing the real economy effect on exchange rate pass-through), NEER, and the indicator of monetary policy stance;

$q_{t}$ is a threshold variable; $\gamma_{1}$ and $\gamma_{2}$ are threshold values; inflation rate is also a threshold variable in the model; $\alpha_{i}, \mathrm{i}=1,2,3$ is a $(3 \mathrm{x} 1)$ constant vector;

$A_{i}(L)=A_{i 1} L+A_{i 2} L^{2}+\cdots+A_{i p} L^{p}$ is a polynomial function of the lag operator $L$

$A_{i j}$ is a $(4 \mathrm{x} 4 \mathrm{p})$-matrix for $\mathrm{j}=1,2,3, \ldots, \mathrm{p}$

I(.) equals 1 if conditions are satisfied and 0 otherwise.

Let $\theta=\left(\propto_{1}, \propto_{2}, \propto_{3}, A_{1}, A_{2}, A_{3},\left(\gamma_{1}, \gamma_{2}\right)\right)$ be a parameter vector. We employ OLS technique to simplify the following function:

$$
\hat{\theta}=\operatorname{argmin}\left(\sum_{t=1}^{T}\left\{\begin{array}{c}
y_{t}-\left(\alpha_{1}+A_{11}(L) y_{t-1}+\cdots+A_{1 p}(L) y_{t-p}+\varepsilon_{1 t}\right) I\left(q_{t} \leq \gamma_{1}\right) \\
-\left(\alpha_{2}+A_{21}(L) y_{t-1}+\cdots+A_{2 p}(L) y_{t-p}+\varepsilon_{2 t}\right) I\left(\gamma_{1}<q_{t} \leq \gamma_{2}\right) \\
-\left(\alpha_{3}+A_{31}(L) y_{t-1}+\cdots+A_{3 p}(L) y_{t-p}+\varepsilon_{3 t}\right) I\left(q_{t}>\gamma_{2}\right)
\end{array}\right)\right.
$$

4.2. Conditional impulse response function (CIRF) versus generalized impulse response function (GIRF)

After the TVAR estimation, we perform an impulse response analysis. In the nonlinear model the response of endogenous variables to a certain shock depends in large part on the past history, the state of the economy, and the extent of the shock to be studied in period zero. The levels and signs of all the shocks have effects on economic performance during the surveyed period, or a shock at period $t$ may trigger a switch of regime at period $t+d$, where $d$ is the estimated lag of the threshold. In this respect we adopt both kinds of functions with mutual effects, including: (i) regime-dependent impulse response function (also known as conditional impulse response functionCIRF); and (ii) generalized impulse response function (GIRF).

The regime-dependent impulse response function or CIRF describes the response of the system to a shock in each regime identified through the inflation threshold that has been estimated. This implies that different responses can only be exhibited in an assumed regime, and CIRF, therefore, is considered the linear response function in the scope of a regime assumed, or an effective tool for displaying the behavior of the system within each regime.

Nevertheless, CIRF may not be compatible with the ultimate macro impact of a shock if the possibility of a shift in regime throughout the cycle of reaction is high enough. This circumstance requires consideration of the nonlinear impulse response analysis, 
which does not assume that the system remains in a certain regime at the start of the shock (Gallant et al., 1993; Koop et al., 1996; Potter, 2000). For instance, a big enough shock for a variable leads to a shift of the economy from the original regime once its direct or indirect effect is powerful enough, and over a course of time the response is able to switch back and forth between two regimes. Generally, the nonlinear impulse response differs from its linear counterpart in that it depends on the history of time series, as well as the extent of the shock.

As stated above, we perform both CIRF and GIRF, and the latter is estimated using bootstrap simulation technique suggested by Balke (2000).

\subsection{Estimation methods}

\subsubsection{Data description}

This study employs seasonally adjusted monthly data over the period from January 2000 to December 2014.

Real effective exchange rate is calculated using bilateral exchange rates between Vietnamese currency and those of 12 nations (also including those in the Eurozone), such as Australia, Cambodia, Hong Kong, China, Singapore, USA, Malaysia, India, South Korea, Japan, Philippines, and Thailand.

The data for bilateral exchange rate and volume of trade are collected from IFS. We define the exchange rate shock as a rising shock of the exchange rate or devaluation of Vietnamese currency in terms of direct quotation for which the research is intended.

Inflation rate is measured by a variance in CPI, commonly adopted for determining the price trend and regarded as one of the best indicators of inflation process in the economy (Brière \& Signori, 2012). CPI is collated from Datastream.

Output gap is estimated using industrial production index by means of the HodrickPrescott filter. The industrial production index is retrieved from General Statistics Office of Vietnam (GSO).

Interbank rate for one-month term, as a proxy for monetary policy, is used instead of rediscount interest rate or refinancing interest rate. Since the interbank rate, according to previous literature, has a more significant impact on the market and macro variables of the economy than other policy rates (Tran \& Nguyen, 2012; Nguyen \& Luc, 2012), we find it suitable and consistent with the monetary policy stance taken up by the central 
bank. The data are also extracted from Datastream. Description of the dataset is provided in Table 1.

\section{Table 1}

Variable description and data sources

\begin{tabular}{lcc}
\hline Variable & Notation & Source \\
\hline REER & NEER & IFS \\
Inflation rate & INF & Datastream \\
Output gap & OG & GSO \\
Interbank interest rate for one-month term & IR & Datastream \\
\hline
\end{tabular}

\subsubsection{Testing for data features}

Before checking the inflation threshold in the TVAR model, we employ Unit Root Test and ADF test for stationarity and AIC for selection of the optimal lag length. The results indicate that the data are stationary time series with the optimal lag length of 3.

\subsubsection{Testing for nonlinearity}

We continue with nonlinearity testing as applied to the TVAR model compared to the linear VAR, in which inflation is used as a threshold variable. The threshold value is a breakpoint at which the exchange rate pass-through statistically significant is replaced by one not statistically significant, or vice versa. To test for the null hypothesis of linearity $(\mathrm{m}=1 ; \mathrm{m}$ is the number of regimes) in comparison with nonlinearity $(\mathrm{m}=2,3$ regimes), we apply the extended multivariate linear hypothesis test as proposed by Hansen (1999), and Lo and Zivot (2001). Also employed is the covariance matrix for each model ( 0 and 1$)$, representing the simple VAR model (with the null hypothesis of linearity) and the TVAR model corresponding to one or two regimes. The LR statistic is defined as follows:

$$
L R_{01}=T\left(\ln \left(\operatorname{det} \widehat{\Sigma}_{0}\right)-T\left(\ln \left(\operatorname{det} \widehat{\Sigma}_{1}\right)\right)\right.
$$

where $\widehat{\Sigma}_{0}$ is estimated covariance matrix of the model under the null hypothesis and $\widehat{\Sigma}_{1}$ is the estimated matrix with other alternatives. The p-value estimation is reliant on bootstrap simulation, which is constructed from the residuals in the model under the null hypothesis besides threshold estimation and further testing. In all estimations we use 1,000 bootstrap replications. 


\section{Table 2}

LR testing results

LR test for linearity against two regimes

\begin{tabular}{lc}
\hline LR statistic & 128.2305 \\
p-value & 0.0000 \\
Estimated threshold & 0.00128
\end{tabular}

LR test for linearity against three regimes

$\begin{array}{lc}\text { LR statistic } & 314.0228 \\ \text { p-value } & 0.0000\end{array}$

Estimated threshold

$0.001595 ; 0.003395$

LR test for two regimes against three regimes

LR statistic

185.7923

p-value

0.0000

Estimated threshold

$0.001595 ; 0.003395$

Notes: $\mathrm{p}$-value $=0$ implies that the null hypothesis is rejected. The first test rejects the linear hypothesis and accepts the nonlinear one with two regimes. The second test rejects the linear hypothesis and accepts the nonlinear one with three regimes. The third test rejects the nonlinear hypothesis with two regimes and accepts the nonlinear one with three regimes.

Accordingly, the Vietnam's economy, as suggested by the empirical results, can be illustrated by a three-regime TVAR model with two estimated thresholds of $0.1595 \% /$ month and $0.3395 \% /$ month. 


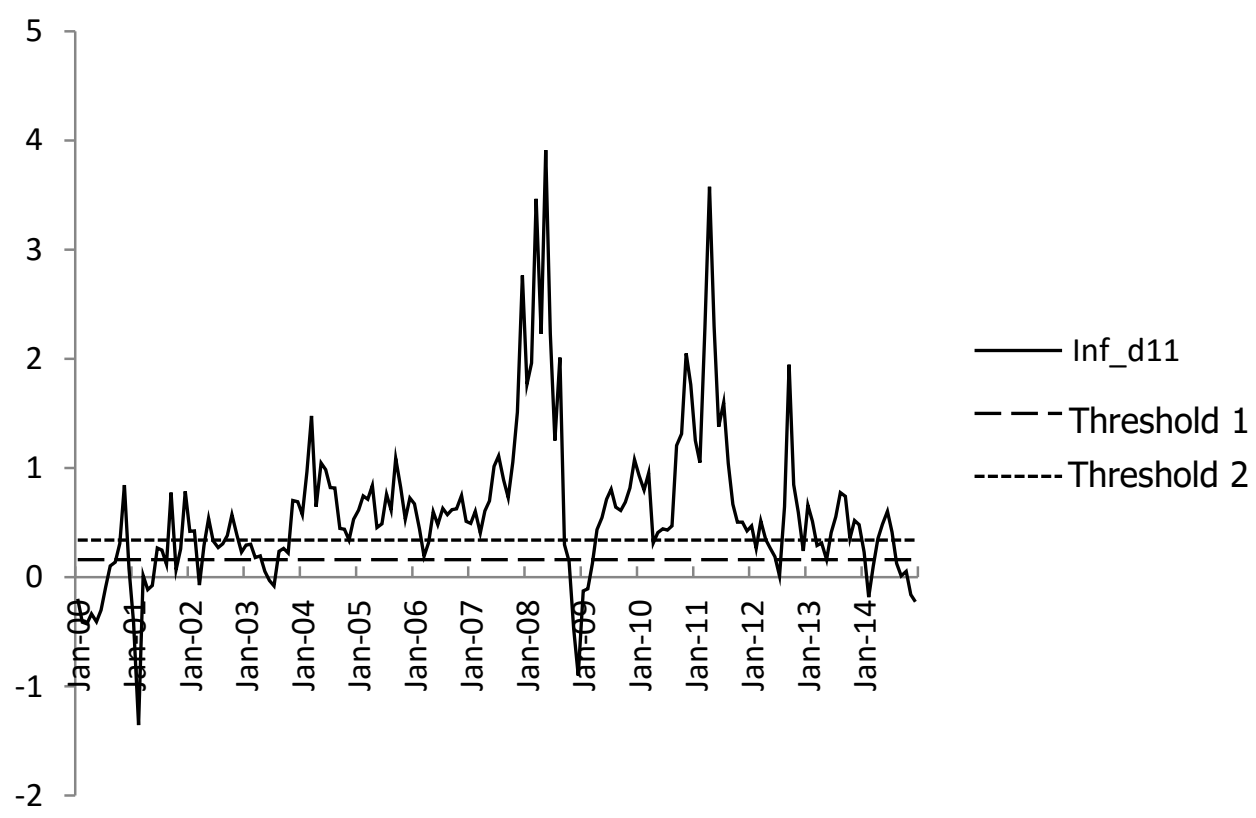

Figure 3. Inflation process with two thresholds

\section{Results and discussion}

\section{Table 3}

Estimated results of TVAR model with inflation (INF) as a threshold variable

\begin{tabular}{|c|c|c|c|c|c|c|}
\hline \multirow{3}{*}{$\begin{array}{l}\text { Percentage } \\
\text { of obs. }\end{array}$} & $\begin{array}{c}\text { Regime } 1 \\
\operatorname{INF}(-1)<=0.001595\end{array}$ & \multicolumn{3}{|c|}{$\begin{aligned} & \text { Regime } 2 \\
< & \operatorname{INF}(-1)<=0.003395\end{aligned}$} & \multicolumn{2}{|c|}{$\begin{array}{c}\text { Regime } 3 \\
\mathrm{INF}(-1)>0.003395\end{array}$} \\
\hline & $18.64 \%$ & \multicolumn{3}{|c|}{$15.82 \%$} & \multicolumn{2}{|c|}{$65.54 \%$} \\
\hline & coefficient tstat pval & coefficient & Tstat & pval & coefficient & Pval \\
\hline Constant & $-0.0047-1.14840 .2643$ & 30.0025 & 3.6952 & 0.0022 & 0.0043 & 2.02620 .0453 \\
\hline $\operatorname{INF}(-1)$ & $\begin{array}{ll}0.3961 & 2.24990 .0359\end{array}$ & 0.0489 & 0.9053 & 0.3796 & 0.4794 & 5.57720 .0000 \\
\hline Output Gap (-1) & $0.0242 \quad 2.34920 .0292$ & $2-0.0032$ & -1.4485 & 0.1681 & 0.0044 & 0.57230 .5684 \\
\hline NEER (-1) & $0.0276 \quad 0.85130 .4047$ & 0.0058 & 0.6536 & 0.5233 & 0.0598 & 2.50940 .0136 \\
\hline $\operatorname{IR}(-1)$ & $-0.0011-0.01670 .9868$ & 0.0078 & 0.7634 & 0.4570 & 0.0645 & 1.79420 .0757 \\
\hline
\end{tabular}




\begin{tabular}{|c|c|c|c|c|c|c|c|}
\hline & & egime 1 & & Regime 2 & & & gime 3 \\
\hline & $\operatorname{INF}(-1)$ & $<=0.0015950$ & $0.001595<1$ & $\operatorname{NF}(-1)<$ & 0.003395 & $5 \quad \operatorname{INF}(-1)$ & $>0.003395$ \\
\hline Percentage & & $8.64 \%$ & & $15.82 \%$ & & & $5.54 \%$ \\
\hline & coefficient & it tstat pval & coefficient & Tstat & pval & coefficient & tstat Pval \\
\hline INF (-2) & -0.0422 & -0.24500 .8089 & -0.0301 & -0.4276 & 0.6750 & -0.0226 & -0.21760 .8281 \\
\hline Output Gap (-2) & -0.0113 & -0.81300 .4258 & 0.0000 & 0.0167 & 0.9869 & $-0.0061-$ & -0.73910 .4615 \\
\hline NEER (-2) & -0.0289 & -0.70490 .4890 & -0.0094 & -0.8877 & 0.3887 & 0.0387 & 1.06270 .2904 \\
\hline IR $(-2)$ & 0.0813 & 0.87250 .3933 & 0.0007 & 0.0513 & 0.9598 & -0.0893 & -2.08690 .0394 \\
\hline $\operatorname{INF}(-3)$ & -0.1587 & -1.28280 .2142 & 0.0109 & 0.3107 & 0.7603 & 0.2825 & 2.97580 .0036 \\
\hline Output Gap (-3) & 0.0056 & 0.68520 .5011 & -0.0002 & -0.0972 & 0.9239 & 0.0036 & 0.44760 .6554 \\
\hline NEER (-3) & 0.0039 & 0.13060 .8974 & 0.0037 & 0.3970 & 0.6970 & -0.0989 & -4.29460 .0000 \\
\hline $\operatorname{IR}(-3)$ & -0.0653 & -0.91790 .3696 & -0.0089 & -0.9391 & 0.3625 & -0.0046 & -0.12660 .8995 \\
\hline AIC & -72.8618 & & & & & & \\
\hline SIC & -67.2618 & & & & & & \\
\hline SSR & 15.0372 & & & & & & \\
\hline
\end{tabular}

Table 3 presents the estimated results of the TVAR model with the use of inflation as the threshold variable. Although two thresholds and three regimes are detected by employing econometric techniques, the coefficients of exchange rate pass-through to inflation rate under the first and second regimes are not statistically significant, whereas those under the third one is statistically significant. A large proportion of observations $(65.54 \%)$ is recorded in the event of the third regime; thus, we focus on the primary threshold of $0.3395 \% /$ month, equivalent to $4.074 \% / y e a r$, below the level of which the pass-through is not statistically significant, or there is no clear evidence of the exchange rate pass-through to inflation. In contrast, above the threshold level a shock of increasing exchange rate may be conducive to a sharp rise in inflation rate in the coming term, which is not vividly shown in another coming term, and the inflation finally reduces in subsequent periods.

The results we obtain from the model are quite consistent with the progress of Vietnam's economy. In a low inflation environment (below the threshold of $0.3395 \%$ ) 
at certain points of time (eg., December 25, 2008; November 25, 2009; and February 10, 2010 when the central bank implemented monetary devaluation strategies), inflation rates reveal no abrupt changes (Figure 4). This illustrates the reasoning behind the research outcome that devaluation of VND is not statistically significant when the inflation rate is below the threshold of $0.3395 \%$. Due to expectations of low inflation rates, businesses do not make price adjustments in the situation of volatile exchange rates. Other contributory factors include the Vietnam's government with its active control over prices of key products, such as gasoline, oil, electricity, and water, and price stabilization programs in such a big urban area as Ho Chi Minh City. In addition, most of the surveyed periods commence after the global financial crisis; thus, weak purchasing power serves to explain why the devaluation has no effects on inflation rates.

Two devaluation attempts have been made in a very high inflation environment (above the threshold of 0.3395\%) as in August 2010 and February 2011. In such an environment where the inflation rate is higher than the defined threshold (third regime), the devaluation plainly has an impact on the inflation as theoretically expected, and only a short time later does the inflation rate reveal another drop (Figure 4). Sharp devaluation, as commonly known, triggers a huge and prolonged rise in inflation, but in fact the behavior of inflation is somewhat alleviated after the shock. The reason is that the official USD/VND rate has been put under control for too long, while the unofficial exchange rate on the traded market is higher than the average interbank rate. The official rate in the research data does not actually exist in transactions on the market over these periods; domestic importers and business households have to purchase US dollars on the informal market. The strong devaluation implemented by the central bank is merely to legalize unofficial rates existing long before. In fact, the inflation rate has increased before the devaluation; thus, its increase after the event signals the fact that it returns to equilibrium.

However, why could the inflation rate constantly reduce, especially after the devaluation attempt in 2011? In our view, the fundamental reason lies in the issuance of Resolution No. 11 on the unprecedented fiscal tightening policy, on account of which commitments have been demonstrated until the present time. That astonishing claim, which rebuilt market confidence, together with the considerable tightening, has allowed for significantly diminishing inflation rates. 


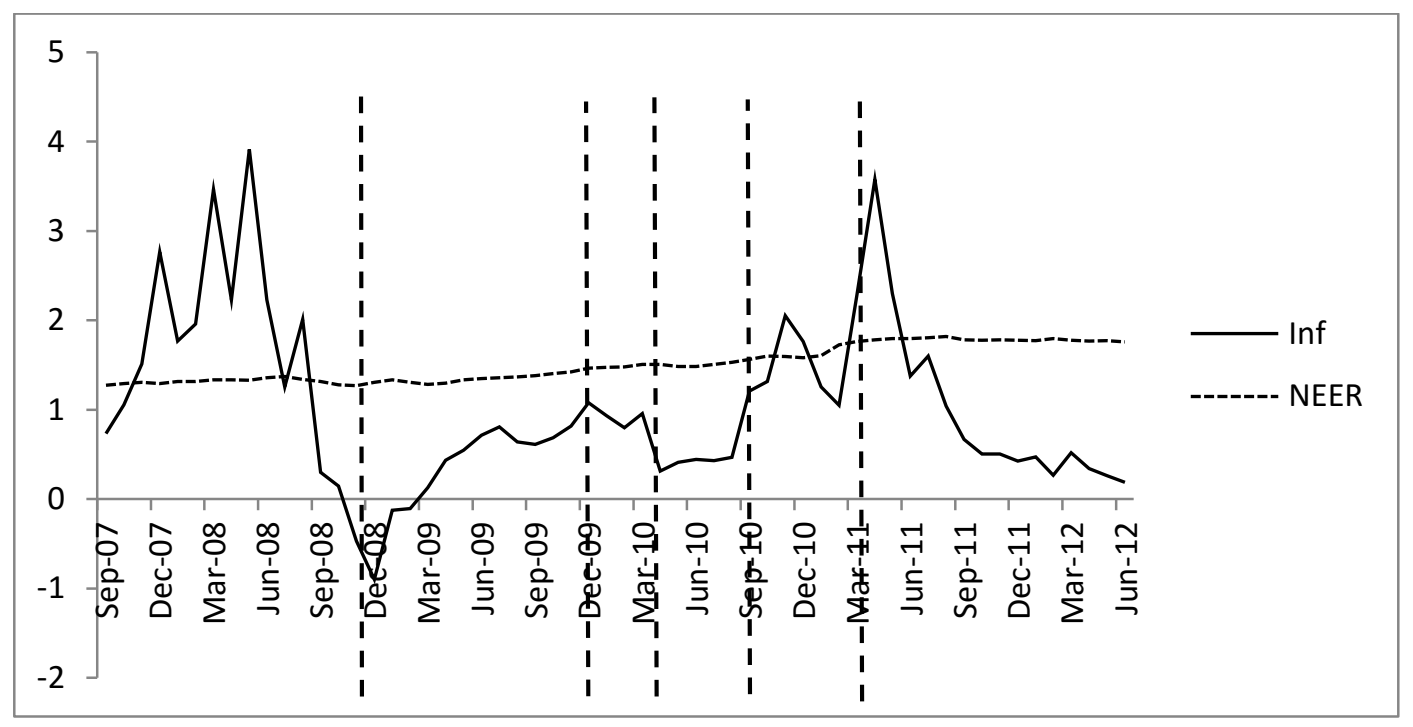

Figure 4. Inflation process under the influence of exchange rate shocks (2008-2011) Note: compiled from IFS and Datastream

To capture exchange rate shocks and their effects on inflation rate, interest rate, and production, we perform impulse response functions, starting with the conditional assumption for each regime (Figure 5).
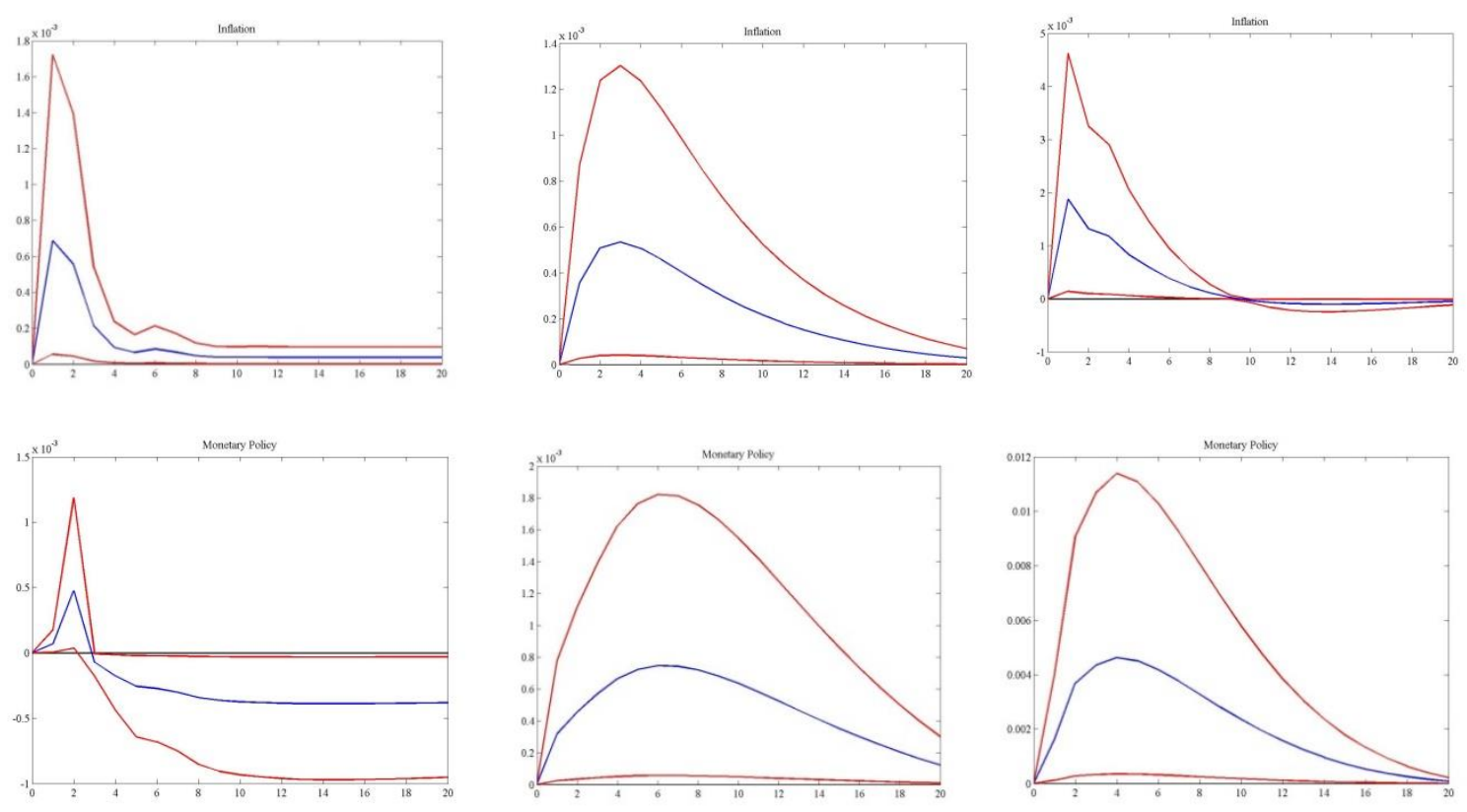

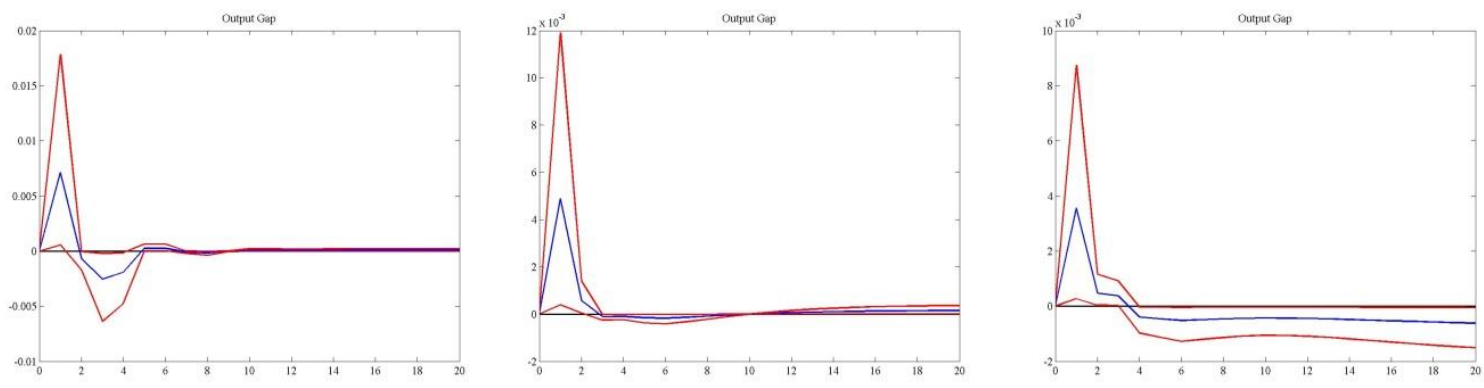

Figure 5. Conditional cumulative impulse responses of inflation, interest rate, and production to exchange rate shocks

Note: The horizontal axis denotes the simulated impulse response duration, whereas the vertical axis is the degree of response to a positive shock of NEER.

The results of impulse response function (Figure 5) suggest that in the first regime with an increase in exchange rate shock by one standard deviation, the inflation rate increases by $0.6 \%$ for more than one coming term and then sharply reduces for eight months later. Concerning the second regime, the exchange rate shock increase by one standard deviation would result in a rise in the inflation rate by approximately $0.6 \%$ for the next two terms and steadily decreases to the equilibrium rate during 20 coming months.

Nevertheless, in the third regime the response of CPI to exchange rate shock is completely different from that in the other regimes. When the shock increases by one standard deviation, the inflation rate soars by nearly $2 \%$ for more than one coming term and falls sharply to the equilibrium rate over 10 months later, followed by a decreasing tendency subsequently.

The downside of conditional impulse response is that it takes into account responses of inflation, interest rate, and production in each regime and assumes that the shock does not cause a shift from one regime to another, which in fact is highly likely if its extent is large enough.

The results of generalized impulse response function (GIRF) are provided in Figure 6 below. 

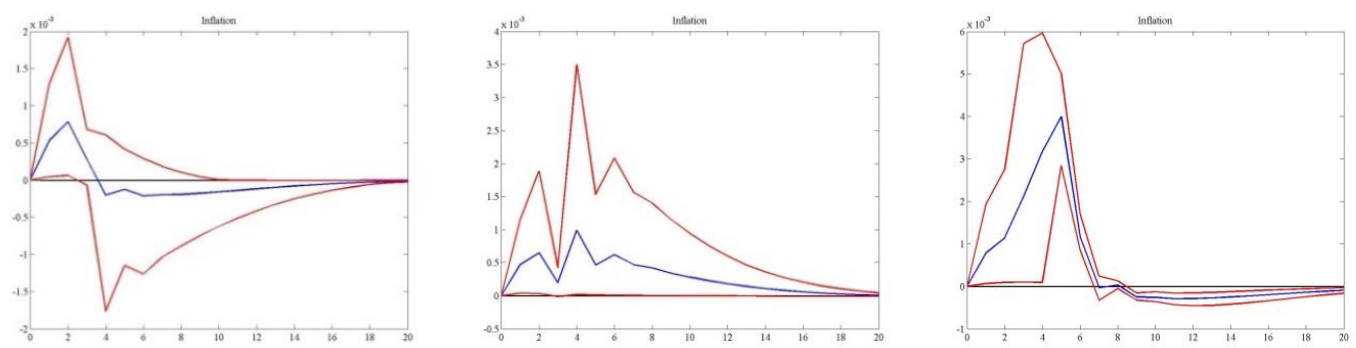

Figure 6a
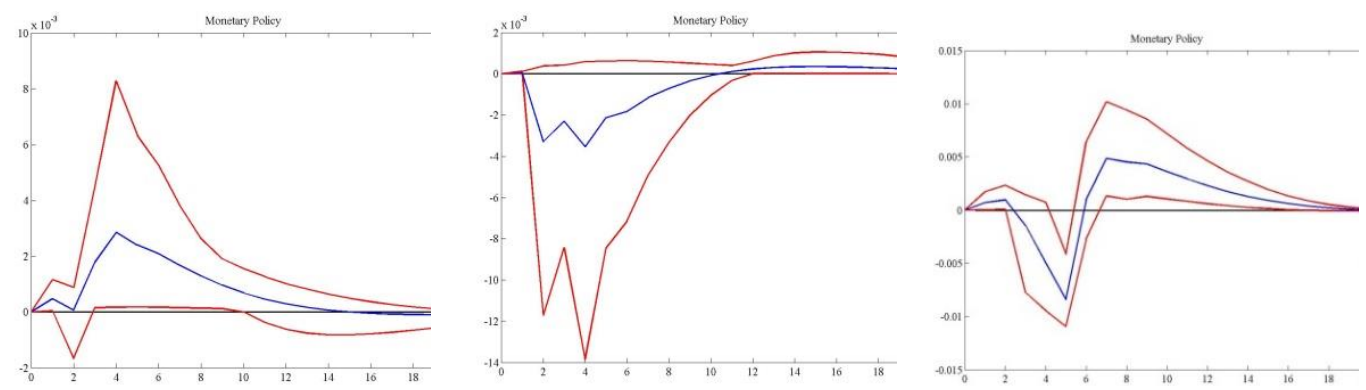

Figure $6 b$
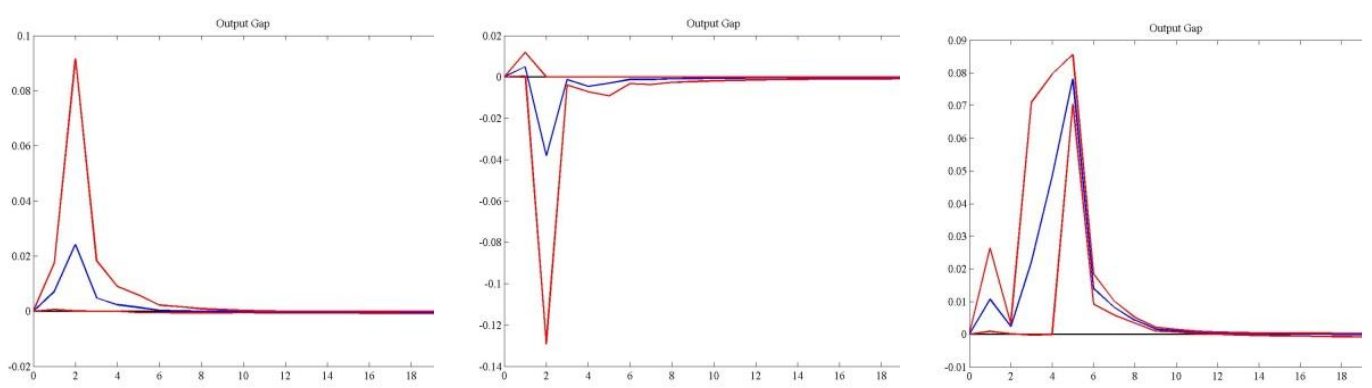

Figure 6c

Figure 6. Generalized Impulse Response Function (GIRF)

Figures $6 \mathrm{a}, 6 \mathrm{~b}$, and $6 \mathrm{c}$ plot the responses of inflation, interest rate, and production to the positive shocks of NEER, respectively, with the assumption that the shocks are shown, corresponding to the first, second, and third regimes.

Accordingly, considering the shifts between various regimes, GIRF differs from CIRF remarkably. The variables in response to exchange rate shocks, not as usual, reveal high volatilities after the shocks and then return to equilibrium. The process of change 
in value under the shock influence is more complicated in different aspects, suggesting a certain switch in the regime. Take, for example, the response of inflation to the exchange rate shock. If the shock occurs in the first regime, then the inflation rate increases, and it is likely that the first regime shifts to the third one along with different responses in later periods.

\section{Conclusion and policy implications}

\subsection{Conclusion}

The paper analyzes the level of exchange rate pass-through to inflation measured by the consumer price index $(C P I)$. Unlike prior studies conducted in the same country, ours investigates whether the exchange pass-through in Vietnam features nonlinearity and whether the inflationary environment has effect on the pass-through coefficient.

As documented by Taylor (2000), low inflation environments, in which economic entities, due to expectations of low inflation rates, made no attempt to adjust their prices for expected returns, are attributed to low pass-through coefficients among industrial countries in the 90s. Contrarily, in a high-inflation environment price-adjustment frequency rises owing to expectations of increased inflation.

In the paper the TVAR approach is adopted besides using inflation, REER, output gap, and interest rate as variables in the equation system. The empirical results in the context of Vietnam underpin Taylor's argument for the nonlinear nexus of exchange rate pass-through to inflation. Two of the inflation thresholds of $0.1595 \% / \mathrm{month}$ and $0.3395 \% /$ month are detected, corresponding to the three stated regimes. Also, due to similar and statistically insignificant pass-through coefficients in the first and second regimes, the paper then focuses on analysis of the second threshold $(0.3395 \% / \mathrm{month})$.

In the regime below the threshold level, with an exchange rate shock, there is no significant change in inflation rate. However, in a high inflation regime (above $0.3395 \%$ /month or $4.074 \%$ /year), the inflation sharply increases and shifts further back to the equilibrium level. The actual inflation processes from depreciation events dating back to 2008 and 2011 in Vietnam are further pinpointed via using both CIRF and GIRF.

\subsection{Policy implications}

A few implications can be drawn from the research results as follows: 
Firstly, in a low inflation environment, the fact that no evidence is found of VND devaluation pass-through to inflation does not imply that the central banks may actively adopt this policy in later times. This is due to the fact that: (i) the Government has taken measure to assume controls over key products, such as gasoline, oil, electricity, and water; (ii) low productivity as well as uncontrollable smuggled goods in a highly open economy diminishes the effect of devaluation policies; and (iii) economic recession weakens the demand, causing significantly low inflation rates. Although gradual marketization has been implemented of the key products, the market's trust in macro management practices has not sufficiently gained. Thus, inflation obsession might be conducive to adverse impact of future devaluation on inflation control.

Secondly, the VND devaluation in a high inflation environment, as suggested by the TVAR estimation, may yield worse results in case the Government wishes to steadily pursue the loosened monetary policy while pressing ahead with ambitious plans for stabilizing the exchange rate by restraining it.

Thirdly, an inflation threshold of roughly 4\%/year through the findings hints that the central bank should implement the policy on the target inflation rate in pursuing monetary policy. Although one objective fact, as suggested by the empirical results, is the Government's controls over primary products, causing a sharp decline in CPI, the market's trust might be built up if the inflation threshold is well maintained below $4 \%$. This calls for a sound policy on managing international capital inflows. Once capital accounts are appropriately settled, the sovereign monetary policy could be followed to reach the target threshold. This implication, in fact, is intended for the impossible trinity toward flexible exchange rate, gradual financial integration, and monetary independence

\section{References}

Al-Abri, A. S., \& Goodwin, B. K. (2009). Re-examining the exchange rate pass-through into import prices using non-linear estimation techniques: Threshold cointegration. International Review of Economics and Finance, 18(1), 142-161.

Aleem, A., \& Lahiani, A. (2014). A threshold vector autoregression model of exchange rate passthrough in Mexico. Research in International Business and Finance, 30, 24-33. doi:10.1016/j.ribaf.2013.05.001

Balke, N. S. (2000). Credit and economic activity: Credit regimes and nonlinear propagation of shocks. The Review of Economics and Statistics, 82(2), 344-349. 
Barhoumi, K. (2006). Differences in the long run exchange rate pass-through into import prices in developing countries: An empirical investigation. Economic Modelling, 23, 926-951.

Brière, M., \& Signori, O. (2012). Hedging inflation risk in a developing economy: The case of Brazil. Research in International Business and Finance, 27(1), 209-222.

Calvo, G. A., \& Reinhart, G. M. (2002). Fear of floating. Quarterly Journal of Economics, 117, 215244.

Campa, J., \& Goldberg, L. S. (2005). Exchange rate pass-through into import prices: A macro or micro phenomenon? The Review of Economics and Statistics, 87(4), 679-690.

Choudhri, E. U., \& Hakura, D. S. (2006). Exchange rate pass-through to domestic prices: Does the inflationary environment matter? Journal of International Money and Finance, 25(4), 614-639.

Devereux, M., \& Yetman, J. (2010). Price adjustment and exchange rate pass-through. Journal of International Money and Finance, 29, 181-200.

Gagnon, J., \& Ihrig, J. (2001). Monetary policy and exchange rate pass-through. International finance discussion paper 704, Board of Governors of the Federal Reserve System. Retrieved from http://www.federalreserve.gov/pubs/ifdp/2001/704/ifdp704.pdf

Gallant, A. R., Rossi, P. E., \& Tauchen, G. (1993). Nonlinear dynamic structures. Econometrica, 61(4), 871-908.

Hansen, B. E. (1999). Testing for linearity. Journal of Economic Surveys, 13, 551-576.

Hubrich, K., \& Teräsvirta, T. (2013). Thresholds and smooth transitions in Vector Autoregressive models. Retrieved from ftp://ftp.econ.au.dk/creates/rp/13/rp13_18.pdf

Junttila, J., \& Korhonen, M. (2012). The role of inflation regime in the exchange rate pass-through to import prices. International Review of Economics and Finance, 24, 88-96.

Koop, G., Pesaran, M. H., \& Potter, S. (1996). Impulse response analysis in nonlinear multivariate models. Journal of Econometrics, 74(1), 119-148.

Lo, M., \& Zivot, E. (2001). Threshold cointegration and nonlinear adjustment to the law of one price. Macroeconomic Dynamics, 5(4), 533-576.

Nguyen, D. M. A., Tran, M. A., \& Vo, T. T. (2010). Exchange rate pass-through into inflation in Vietnam: An assessment using vector autoregression approach. Retrieved from http://documents.mx/documents/final-exchange-rate-pass-through-to-inflation-in-vietnamonjournalpdf.html

Nguyen, T. N. T., \& Luc, V. C. (2012). Exchange rate shift to domestic prices in Vietnam (in Vietnamese). Journal of Development and Integration, 7(17), 7-13.

Nguyen, T. N. T., \& Nguyen, H. T. (2014). Monetary policy transparency and retail interest rate passthrough in Vietnam (in Vietnamese). Journal of Development and Integration, 15(25), 11-17.

Nguyen, T. T. H., \& Nguyen, D. T. (2010). Macroeconomic determinants of Vietnam's inflation 2000-2010: Evidence and analysis. VEPR Working Paper, 2010. 
Potter, S. (2000). Nonlinear impulse response functions. Journal of Economic Dynamics and Control, 24(10), 1425-1446.

Taylor, J. (2000). Low inflation, pass-through and the pricing power of firms. European Economic Review, 44, 1389-1408.

Tran, N. T., \& Nguyen, H. T. (2012). A preliminary investigation into currency devaluation and a few policy implications for Vietnam (in Vietnamese). Institution-level research paper. Ho Chi Minh City, Vietnam: University of Economics.

Tran, N. T., \& Nguyen, H. T. (2013). Transmission mechanism of monetary policy in Vietnam approached by SVAR technique (in Vietnamese). Journal of Development and Integration, $10(20), 8-16$.

Vo, V. M. (2009). Exchange rate pass-through and its implication for inflation in Vietnam (Working Paper No.0902). Retrieved from http://www.vdf.org.vn/workingpapers/vdfwp0902 